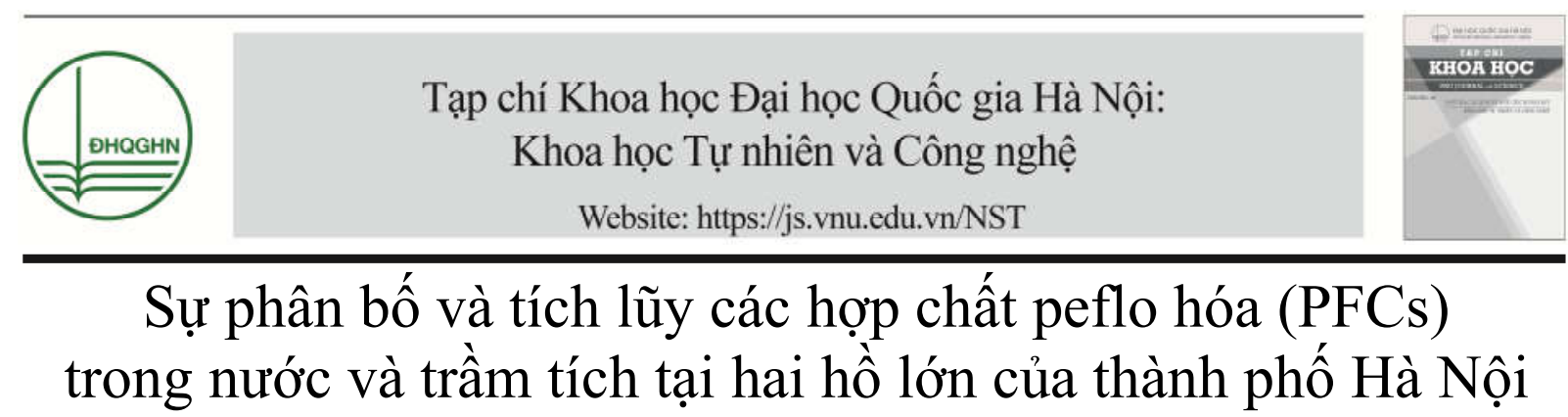

\author{
Nguyễn Thúy Ngọc, Phan Đình Quang, Trương Thị Kim, \\ Phùng Thị Vĩ, Phạm Hùng Việt, Dương Hồng Anh* \\ Phòng thí nghiệm Trọng điểm Công nghệ Phân tích phục vụ kiểm định môi trừ̀ng và an toàn thực phẩm \\ Truòng Đại hoc Khoa học Tự nhiên, ĐHQGHN
}

Nhận ngày 16 tháng 8 năm 2017

Chỉnh sửa ngày 20 tháng 9 năm 2017; Chấp nhận đăng ngày 23 tháng 3 năm 2018

\begin{abstract}
Tóm tắt: Các hợp chất peflo hóa (PFCs) được phân tích trong 40 mẫu nước và 36 mẫu trầm tích được lấy tại hai hồ lớn tại Hà Nội là hồ Tây và hồ Yên Sở trong 2 mùa mưa và mùa khô. Nồng độ trung bình tổng PFCs phát hiện được trong nước hồ Tây là $10,78 \mathrm{ng} / \mathrm{l}(8,13-13,25 \mathrm{ng} / \mathrm{l})$ và trong nước hồ Yên Sở là $14,55 \mathrm{ng} / \mathrm{l}(12,42-17,64 \mathrm{ng} / \mathrm{l})$. Hàm lượng PFCs trung bình trong trầm tích hồ Tây là $0,11 \mathrm{ng} / \mathrm{g}$ mẫu khô $(0,03-0,26 \mathrm{ng} / \mathrm{g}$ mẫu khô $)$ và hồ Yên Sở là $0,79 \mathrm{ng} / \mathrm{g}$ mẫu khô $(0,08-$ $2,01 \mathrm{ng} / \mathrm{g}$ mẫu khô). Tại cả hai hồ, các PFCs được tìm thấy trong nước chủ yếu có số nguyên tử cacbon trong phân tử thấp (từ $\mathrm{C} 4$ đến $\mathrm{C} 10$ ), còn trong trầm tích các cấu tử $\mathrm{C} 8$ đến $\mathrm{C} 10$ chiếm thành phần chính. Có sự tích lũy các PFCs trong nước và trầm tích tại hai hồ Tây và Yên Sở với hệ số phân bố $\mathrm{PFCs}$ giữa trầm tích và nước $\left(\log \mathrm{K}_{\mathrm{D}}\right)$ trong khoảng 1,05 tới 2,91.
\end{abstract}

Tù khóa: PFCs, nước, trầm tích, hồ Yên Sở, hồ Tây.

\section{Mở đầu}

Nhóm hợp chất peflo hóa (PFCs) được sản xuất từ những năm 1950 và sử dụng rộng rãi trong các ngành công nghiệp và sản phẩm sinh hoạt. Do hội đủ các tính chất của các chất ô nhiễm hữu cơ bền vững nên một số chất thuộc nhóm PFCs bao gồm muối peflooctansunfonat (PFOS) và peflooctansunfonyl florua (PFOSF) đã được bổ sung vào Phụ lục $\mathrm{B}$ của Công ước Stockholm năm 2009... Ở Việt Nam, mặc dù

\footnotetext{
*Tác giả liên hệ. ĐT.: 84-.

Email:

https://doi.org/10.25073/2588-1140/vnunst.4708
}

không có sản xuất PFCs nhưng các sản phẩm có khả năng chứa $\mathrm{PFCs}$ được nhập khẩu và sử dụng dưới 3 dạng chính là nhóm sản phẩm tiêu dùng, sản phẩm chuyên dụng như vật liệu trong bình dập lửa, dầu thủy lực, thuốc diệt côn trùng và hóa chất dùng trong ngành dệt may, ngành giấy, chất tẩy sơn, vecni... [1]. Sử dụng các sản phẩm tiêu dùng và quá trình thải bỏ sẽ là nguyên nhân tiềm tàng dẫn đến sự phát tán, vận chuyển và tích lũy các hợp chất PFC trong môi trường ở các nước nói chung trong đó có Việt Nam.

Nhiều nghiên cứu chỉ ra rằng nhà máy xử lý nước thải nói chung là nguồn quan trọng chứa các $\mathrm{PFCs}$, đặc biệt là $\mathrm{PFOS}$ và peflooctanoic axit (PFOA) ảnh hưởng tới hệ sinh thái nước 
[2]. Có những nghiên cứu mô hình cũng cho thấy nhà máy xử lý nước thải là nguồn chính của các chất PFCs trong môi trường nước ở đô thị $[3,4]$. Hiện nay, nước thải đô thị Hà Nội chỉ được xử lý khoảng một phần ba, còn đều thải ra các cống thoát, kênh mương, hồ, ao. Trong hệ thống thoát nước thải đô thị tại Hà Nội, hồ, ao được coi là bộ phận tiếp nhận, điều hòa nước mưa, nước thải và tự làm sạch. Sự tồn lưu và ô nhiễm nhóm hợp chất peflo hóa trong nước và trầm tích của các hồ từ nguồn ô nhiễm nước thải sinh hoạt và sản xuất của thành phố là không thể tránh khỏi. Nghiên cứu đã tiến hành thu thập mẫu nước và trầm tích tại hai hồ lớn nhất của thành phố là hô Tây và hồ Yên Sở vào mùa mưa và mùa khô trong năm để đánh giá mức độ ô nhiễm, sự phân bố cũng như tích lũy nhóm hợp chất PFCs trong hệ sinh thái nước của hai hồ này. 12 hợp chất PFCs được định lượng trong nghiên cứu này bao gồm 9 chất axit pefloankyl từ $\mathrm{C} 4$ đến $\mathrm{C} 12$ và 3 chất muối pefloankyl sulfonat $\mathrm{C} 4, \mathrm{C} 6$ và $\mathrm{C} 8$.

\section{Thực nghiệm}

\section{1. Địa điểm và phưong pháp lấy mẫu}

Hồ Tây - hồ nước tự nhiên lớn nhất trong nội thành Hà Nội với diện tích 530 ha là hồ nước ngọt có nhiệm vụ điều phối nước mưa và là nơi nuôi trồng thủy sản. Mỗi ngày, hồ đang tiếp nhận khoảng $10.000 \mathrm{~m}^{3}$ nước thải sinh hoạt của các hộ dân xung quanh. Hồ Yên Sở là một quần thể các hồ chứa nhỏ nằm ở phía Nam của thủ đô Hà Nội với diện tích mặt nước cỡ 70 ha. Hồ Yên Sở nằm ở vị trí phía Nam Hà Nội, là nơi tiếp nhận nước thải và nước mưa từ các sông Tô Lịch, Lừ, Sét, Kim Ngưu được dẫn vào hồ; chỉ một phần nhỏ nước thải cỡ $200.000 \mathrm{~m}^{3} /$ ngày được xử lý tại nhà máy xử lý nước thải Yên Sở. Nguồn phát tán chất thải dự kiến có thể đưa PFCs vào môi trường các hồ chính là PFCs trong nước thải đô thị, ở Hà Nội đây là nguồn hỗn hợp bao gồm cả nước thải sinh hoạt, nước thải cơ sở sản xuất...

Lấy mẫu: Mẫu nước và trầm tích mặt được lấy tại 10 điểm trong hồ Tây và 10 điểm tại hồ
Yên Sở vào mùa mưa và mùa khô năm 2016. Nước hồ được lấy tại tầng nước mặt và đựng vào chai polyethylene $(\mathrm{PE})$. Trầm tích cũng là trầm tích mặt và được lấy bằng gầu lấy mẫu chuyên dụng. Độ ẩm của mẫu trầm tích được xác định tại $105^{\circ} \mathrm{C}$ sau khi mang về phòng thí nghiệm.

2.2. Xư lý mẫu: Mẫu nước được xử lý theo qui trình chuẩn quốc tế ISO 25101, 2009 [5]. $500 \mathrm{ml}$ mẫu nước được chiết làm sạch và làm giàu bằng kỹ thuật chiết pha rắn sử dụng cột trao đổi anion yếu (cột WAX, Oasis). Các PFCs trên cột WAX được rửa giải bằng $4 \mathrm{ml}$ dung dịch $0,1 \%$ amoniac trong metanol. Mẫu trầm tích ướt $5 \mathrm{~g}$ được xử lý theo tài liệu hướng dẫn của Dự án hợp tác với trường Đại học Liên hợp quốc (UNU) [6]. Mẫu trầm tích được chiết siêu âm 3 lần bằng metanol $20 \%$ trong nước. Dịch chiết đó được ly tâm để loại hết cặn lơ lửng và cho chảy qua cột trao đổi anion yếu WAX, Oasis. 4ml dung dịch $0,1 \%$ amoniac trong methanol được dùng để rửa giải các PFCs. Các dịch chiết pha rắn được cô về $1 \mathrm{ml}$ bằng khí $\mathrm{N}_{2}$ và lọc qua màng lọc nylon $0,2 \mu \mathrm{m}$ vào lọ $1,5 \mathrm{ml}$. Toán hàm lượng PFCs trên khối lượng trầm tích khô dựa trên độ ẩm của mỗi mẫu trầm tích đã được xác định.

2.3.. Phân tích LC-MS/MS: Các PFCs được phân tích định tính và định lượng bằng thiết bị sắc ký lỏng ghép nối khối phổ hai lần LCMS/MS 8040, Shimadzu, Nhật Bản, sử dụng cột tách: Shim-pack FC-ODS C18-ACF3 $(100 \mathrm{~mm} \times 2,2 \mu \mathrm{m})$, chương trình dung môi với pha động A: $2 \mathrm{mmol} / \mathrm{L}$ dung dịch amoni axetat/metanol tỉ lệ thể tích 9:1 và pha động $B$ : metanol [6]. Đường chuẩn được dựng theo phương pháp nội chuẩn trong khoảng nồng độ từ 0,5 đến $20 \mathrm{ng} / \mathrm{ml}$, với hệ số tương quan $\left(\mathrm{R}^{2}\right)>0,99$.

2.4. $Q A / Q C$ : Hỗn hợp chất chuẩn gốc được sử dụng là hỗn hợp PFAC-MXB 2ppm (Wellington Lab) gồm 13 hợp chất axit peflocacboxylic (từ $\mathrm{C} 4-\mathrm{C} 14, \mathrm{C} 16$ và $\mathrm{C} 18$ ) và 4 hợp chất pefloankyl sunfonat $(\mathrm{C} 4, \mathrm{C} 6, \mathrm{C} 8$ và C10). Dung dịch nội chuẩn gốc MPFAC-MXA $2 \mathrm{ppm}$ của hãng Wellington lab là hỗn hợp được đánh dấu ${ }^{13} \mathrm{C}$ của 7 hợp chất axit pefluoroalky 
lcarboxylic (bao gồm C4, C6, C8, C9, C10, C11 và $\mathrm{C} 12$ ) và đánh dấu ${ }^{18} \mathrm{O},{ }^{13} \mathrm{C}$ của 2 hợp chất perfluoroalkylsulfonate (bao gồm $\mathrm{C} 6$ và $\mathrm{C} 8$ ). Dung dịch nội chuẩn được thêm vào mỗi mẫu vào để kiểm soát quá trình phân tích của từng mẫu. Mẫu trắng được thực hiện trong mỗi mẻ mẫu và mẫu thêm chuẩn được kiểm tra ít nhất sau 10 mẫu được xử lý. Trong một mẻ bơm mẫu trên thiết bị LC-MS/MS, dung dịch chuẩn luôn được kiểm tra sau 10 lần bơm mẫu. Giới hạn định lượng đối với 12 PFCs dao động từ 0,06 đến $0,6 \mathrm{ng} / 1$ cho mẫu nước và từ 0,01 đến $0,06 \mathrm{ng} / \mathrm{g}$ cho mẫu trầm tích [7]. Hiệu suất thu hồi các $\mathrm{PFCs}$ trong mẫu nước nằm trong khoảng $87-112 \%$. Đối với mẫu trầm tích, qui trình phân tích đáng tin cậy cho 10 hợp chất PFCs với hiệu suất thu hồi từ $80-121 \%$ (3 $16 \% \mathrm{CV}$ ) ngoại trừ $\mathrm{PFUdA}$ và $\mathrm{PFDoA}$.

\section{Kết quả và thảo luận}

\subsection{Nồng độ và sự phân bố PFCs trong nước:}

Nồng độ trung bình của tổng $12 \mathrm{PFC}$ được phân tích trong 20 mẫu nước mặt hồ Tây là $10,78 \mathrm{ng} / 1$ nằm trong khoảng 8,13 đến 13,25 ng/1 và trong 20 mẫu nước mặt hồ Yên Sở là $14,55 \mathrm{ng} / \mathrm{l}$ dao động trong khoảng 12,42 đến $17,64 \mathrm{ng} / \mathrm{l}$. Nồng độ tổng PFC trong nước hồ Yên Sở tìm thấy cao hơn hồ Tây (hình 1). Điều này dễ dàng giải thích do hồ Yên Sở là nơi tiếp nhận chủ yếu nước thải sinh hoạt của thành phố. Ở từng hồ khi so sánh kết quả hai mùa không thấy có sự khác biệt về nồng độ tổng $\mathrm{PFC}$ quan trắc được trong nước giữa mùa khô và mừa mưa $(\mathrm{p}<0,05)$.

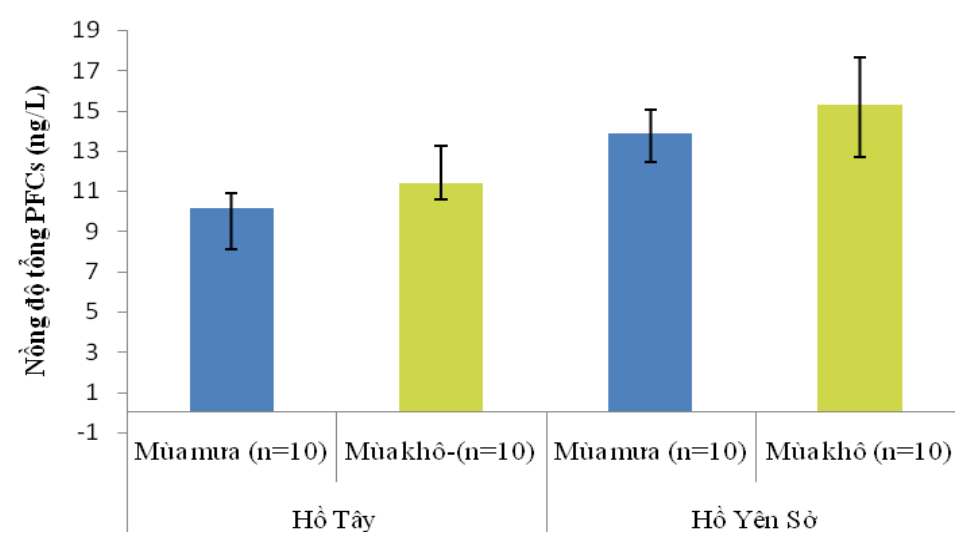

Hình 1. Nồng độ trung bình tổng 12 PFCs tại hồ Tây và Yên Sở.

Tại hồ Tây, sự phân bố thành phần các PFC trong nước giống nhau trong cả hai mùa quan trắc cho thấy nguồn chất ô nhiễm chảy vào hồ Tây không có sự thay đổi nhiều cũng như dung lượng lớn của hồ. Các PFC chiếm tỷ lệ cao nhất trong số 12 chất phân tích là PFBA (cỡ 30\% của tổng $\mathrm{PFCs})$, PFOA $(25 \%)$ và $\mathrm{PFHxA}$ $(20 \%)$. Nồng độ trung bình của PFOA $(2,48$ $\mathrm{ng} / \mathrm{l})$ cao hơn sáu lần nồng độ PFOS $(0,42 \mathrm{ng} / \mathrm{l})$ trong nước hồ Tây.

Tại hồ Yên Sở, thành phần của các $\mathrm{PFC}$ trong nước khá thay đổi trong 2 mùa quan trắc (hình 2) do ảnh hưởng trực tiếp của nước thải thành phố và nước mưa. Trong mùa khô, các PFC chiếm thành phần cao nhất là PFBS $(38 \%$ của tổng PFCs), PFOA (27\%), PFHxA (22\%) và $\mathrm{PFBA}(20 \%)$, còn trong mùa mưa thứ tự là PFOA $(32 \%)$ và PFBA $(32 \%)$. Nồng độ trung bình của PFOA $(2,93 \mathrm{ng} / \mathrm{l})$ cao hơn sáu lần nồng độ PFOS $(0,46 \mathrm{ng} / \mathrm{l})$ trong nước hồ Yên Sở. Nhìn chung, tại cả hai hồ các cấu tử PFC phát hiện được với tần suất cao là axit pefloankyl có số nguyên tử cacbon trong phân tử thấp từ $\mathrm{C} 4$ đến $\mathrm{C} 9$ (tần suất $80-100 \%$ ) và PFOS với tần suất $90 \%$. 

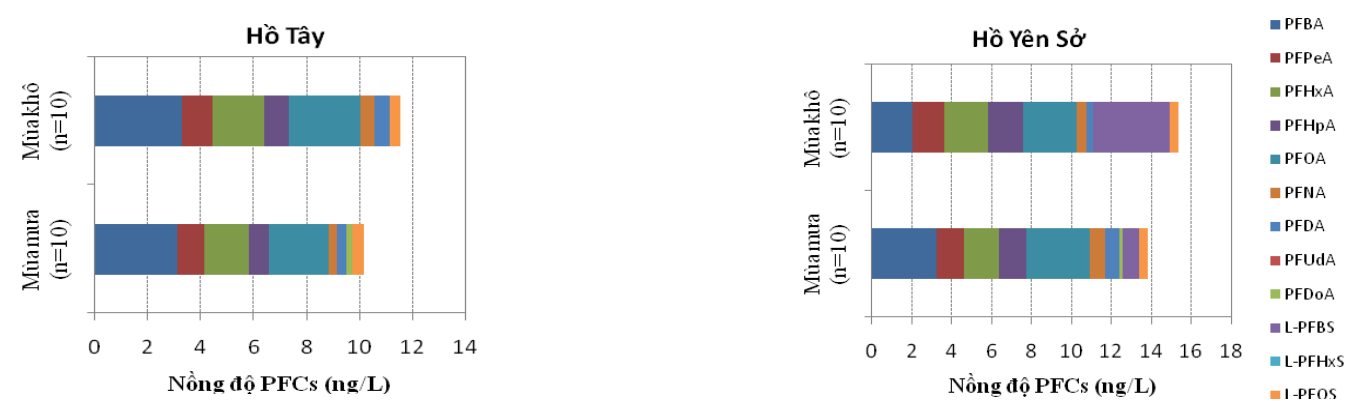

Hình 2. Sự phân bố các PFCs trong nước hồ Tây và hồ Yên Sở.

3.2. Nồng độ và sự tích lũy PFCs trong trầm tích:

Trong trầm tích hồ Tây, hầu hết 7 hợp chất axit pefloankylcacboxylic và 3 hợp chất pefloankylsulfonat đều không phát hiện được hoặc phát hiện thấy ở hàm lượng rất thấp. Hàm lượng trung bình của tổng PFCs là $0,12 \mathrm{ng} / \mathrm{g}$ $(0,03-0,26 \mathrm{ng} / \mathrm{g})$ trầm tích khô vào mùa mưa và $0,10 \mathrm{ng} / \mathrm{g}(0,04-0,20 \mathrm{ng} / \mathrm{g})$ trầm tích khô vào mùa khô. Hàm lượng trung bình tổng các PFC phân tích được trong trầm tích hồ Yên Sở vào mùa mưa là $0,76 \mathrm{ng} / \mathrm{g}(0,12-2,01 \mathrm{ng} / \mathrm{g})$ và vào mùa khô là $0,82 \mathrm{ng} / \mathrm{g}(0,08-1,75 \mathrm{ng} / \mathrm{g})$.
Như vậy tương tự với mẫu nước, hàm lượng PFC trong trầm tích hồ Yên Sở được tìm thấy cao hơn so với trong trầm tích hồ Tây (bảng 1). Tỷ lệ phần trăm phân bố các $\mathrm{PFC}$ trong trầm tích hồ Yên Sở thay đổi trong 2 mùa. Tuy nhiên, cấu tử chiếm thành phần cao cao nhất là PFDA lại khá ổn định gần $50 \%$ trên tổng các PFCs trong cả mùa mưa và mùa khô (hình 3 ). Trong các mẫu phát hiện thấy $\mathrm{PFC}$, các hợp chất có số cacbon từ $\mathrm{C} 8$ đến $\mathrm{C} 10$ là phổ biến với tần suất xuất hiện $>50 \%$ so với các hợp chất có số cacbon thấp.

Bảng 1 . Hàm lượng trung bình và khoảng hàm lượng của các $\mathrm{PFC}$ trong trầm tích tại hồ Yên Sở và hồ Tây (ng/g mẫu khô)

\begin{tabular}{|c|c|c|c|c|c|}
\hline \multirow{2}{*}{ STT } & \multirow{2}{*}{ Tên chất } & \multicolumn{2}{|l|}{ Hồ Yên Sở } & \multicolumn{2}{|l|}{ Hồ Tây } \\
\hline & & Mùa mưa $(\mathrm{n}=8)$ & Mùa khô (n=8) & Mùa mưa $(n=10)$ & Mùa khô $(n=10)$ \\
\hline 1 & PFBA & $<0,03$ & $\begin{array}{l}0,04 \\
(<0,03-0,06)\end{array}$ & $\begin{array}{l}0,07 \\
(<0,03-0,07)\end{array}$ & $\begin{array}{l}0,05 \\
(<0,03-0,09)\end{array}$ \\
\hline 2 & PFPeA & $<0,01$ & $\begin{array}{l}0,06 \\
(<0,01-0,15)\end{array}$ & $\begin{array}{l}0,03 \\
(<0,01-0,04)\end{array}$ & $\begin{array}{l}0,03 \\
(<0,01-0,04)\end{array}$ \\
\hline 3 & PFHxA & $\begin{array}{l}0,07 \\
(<0,01-0,12)\end{array}$ & $\begin{array}{l}0,15 \\
(<0,01-0,15)\end{array}$ & $<0,01$ & $<0,01$ \\
\hline 4 & PFHрA & $<0,01$ & $<0,01$ & $<0,01$ & $<0,01$ \\
\hline 5 & PFOA & $\begin{array}{l}0,14 \\
(0,01-0,45)\end{array}$ & $\begin{array}{l}0,10 \\
(<0,01-0,38)\end{array}$ & $\begin{array}{l}0,05 \\
(<0,01-0,09)\end{array}$ & $\begin{array}{l}0,02 \\
(<0,01-0,04)\end{array}$ \\
\hline 6 & PFNA & $\begin{array}{l}0,11 \\
(<0,01-0,27)\end{array}$ & $\begin{array}{l}0,11 \\
(<0,01-0,31)\end{array}$ & $\begin{array}{l}0,05 \\
(<0,02-0,07)\end{array}$ & $\begin{array}{l}0,04 \\
(<0,01-0,08)\end{array}$ \\
\hline 7 & PFDA & $\begin{array}{l}0,44 \\
(0,01-1,19)\end{array}$ & $\begin{array}{l}0,59 \\
(0,01-1,13)\end{array}$ & $\begin{array}{l}0,04 \\
(<0,03-0,07)\end{array}$ & $\begin{array}{l}0,06 \\
(0,04-0,08)\end{array}$ \\
\hline 8 & L-PFBS & $<0,06$ & $\begin{array}{l}0,06 \\
(<0,06-0,08)\end{array}$ & $<0,06$ & $<0,06$ \\
\hline 9 & L-PFHxS & $<0,06$ & $<0,06$ & $<0,06$ & $<0,06$ \\
\hline 10 & L-PFOS & $\begin{array}{l}0,13 \\
(<0,02-0,32)\end{array}$ & $\begin{array}{l}0,12 \\
(<0,02-0,26)\end{array}$ & $\begin{array}{l}0,05 \\
(<0,02-0,07)\end{array}$ & $\begin{array}{l}0,04 \\
(<0,02-0,05)\end{array}$ \\
\hline & Tổng PFCs & $\begin{array}{l}0,76 \\
(0,12-2,01)\end{array}$ & $\begin{array}{l}0,82 \\
(0,08-1,75)\end{array}$ & $\begin{array}{l}0,12 \\
(0,03-0,26)\end{array}$ & $\begin{array}{l}0,10 \\
(0,04-0,20)\end{array}$ \\
\hline
\end{tabular}




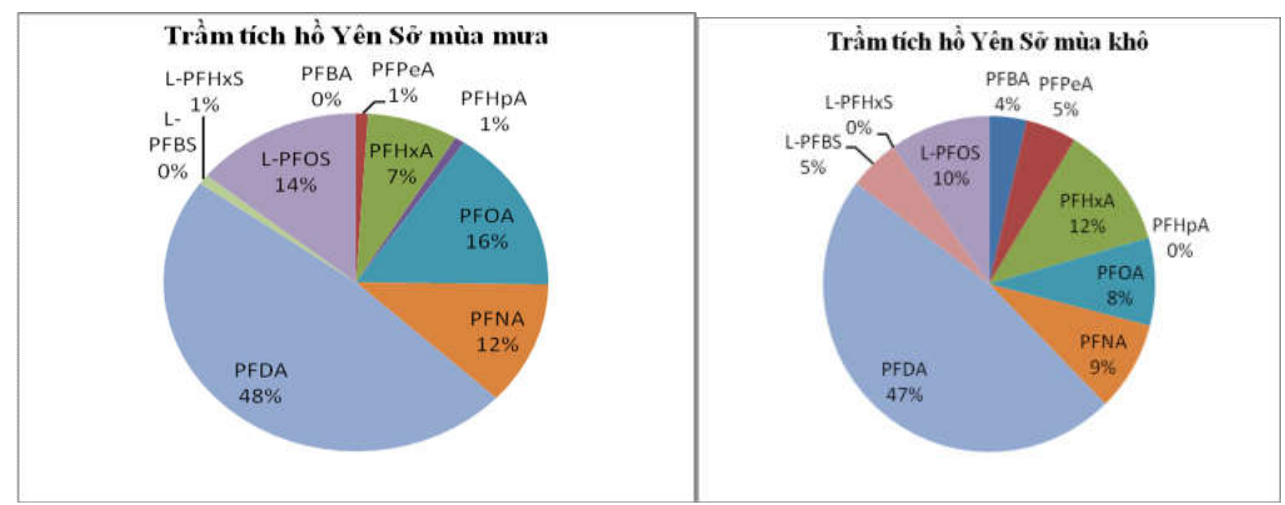

Hình 3. Tỷ lệ phần trăm các loại PFCs trong trầm tích hồ Yên Sở

Số liệu về hai chất PFC được quan tâm nhất là $\mathrm{PFOS}$ và $\mathrm{PFOA}$ trong nước và trầm tích ở hồ Tây và hồ Yên Sở ở Việt Nam khi so sánh với một số hồ lớn trên thế giới như hồ Baiyangdian, Trung Quốc [8], hồ Dianchi, Trung Quốc [9], hồ Taihu, Trung Quốc [10], hồ công viên
Albufera, Tây Ba Nha [11], Michgan, Mỹ [12], được biểu diễn trong hình 4 . Có thể thấy hiện trạng tích lũy của $\mathrm{PFOS}$ và $\mathrm{PFOA}$ trong môi trường nước và trầm tích tại hồ Tây và hồ Yên Sở ở mức thấp hơn so với với tại các hồ lớn trên thế giới.

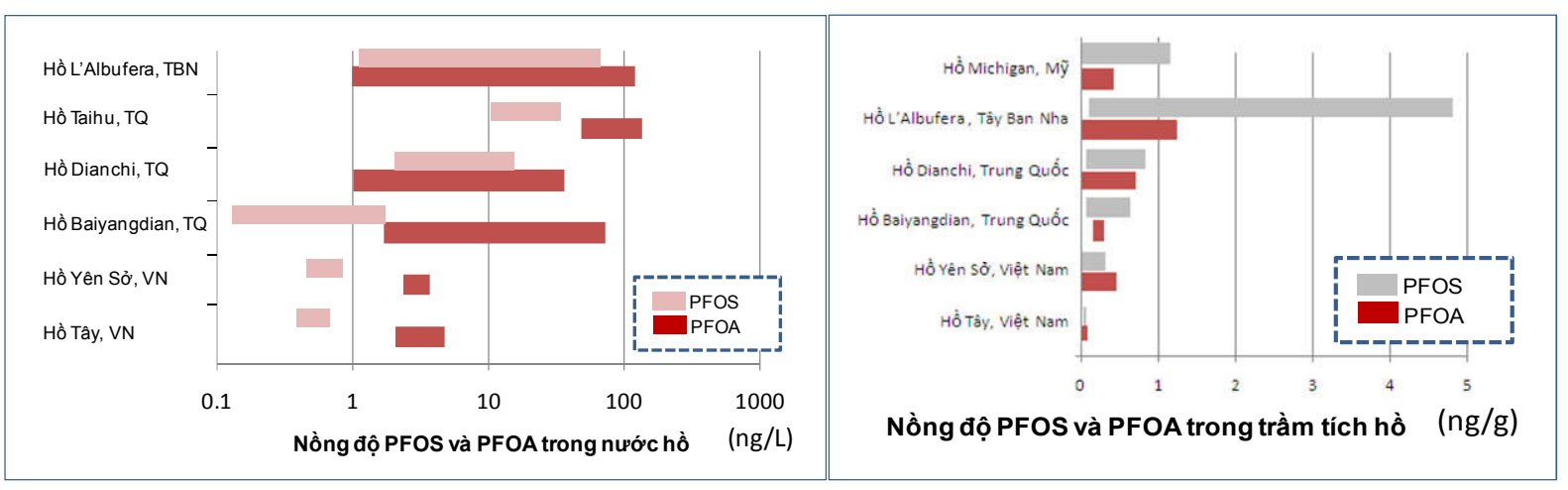

Hình 4. Nồng độ PFOS, PFOA trong nước và trầm tích một số hồ trên thế giới.

\subsection{Hệ số phân bố PFCs giũa trầm tích và nước:}

Như bất cứ một chất hóa học nào, khi cùng tồn tại trong môi trường nước và rắn thì luôn có sự phân bố giữa hai pha. Trong hệ thủy quyển kín, tùy thuộc vào nồng độ của chất đó trong môi trường nước, tính chất hóa lý và điều kiện môi trường mà có sự tích lũy hay hấp phụ vào môi trường trầm tích khác nhau. Hệ số phân bố $\mathrm{K}_{\mathrm{D}}$ của một chất giữa hai pha trầm tích và nước được tính như sau:

$\mathrm{K}_{\mathrm{D}}$ : hệ số phân bố hàm lượng $\mathrm{PFCs}$ giữa trầm tích và nước $\left(\mathrm{K}_{\mathrm{D}}=\mathrm{C}_{\mathrm{PFC} C \text { stràm tích }} / \mathrm{C}_{\mathrm{PFC} \text { snước }}\right)$
Tại hồ Tây, hàm lượng PFCs trong trầm tích khá nhỏ hầu như không phát hiện được, với một số mẫu tồn tại cả $P F C$ trong nước và trầm tích, kết quả tính hệ số phân bố trong trầm tích và nước của các $\mathrm{PFCs}$ có giá trị $\log \mathrm{K}_{\mathrm{D}}$ trong khoảng 1,05 tới 2,10. Tại hồ Yên Sở, hệ số phân bố $\mathrm{PFCs}$ giữa trầm tích và nước có giá trị $\log \mathrm{K}_{\mathrm{D}}$ từ 1,08 tới 2,91. Trong dãy các pefloankyl axit từ PFBA tới PFDA có nhận thấy sự tăng giá trị $\mathrm{K}_{\mathrm{D}} \mathrm{khi}$ tăng chiều dài mạch cacbon. 
Tạp chí Khoa học ĐHQGHN: Khoa học Tự nhiên và Công nghệ, Tập 34, Số 1 (2018) 31-37

Bảng 3. Sự phân bố PFCs giữa nước và trầm tích hồ Tây và hồ Yên Sở

\begin{tabular}{llllll}
\hline STT & Tên chất & Hồ Tây & \multicolumn{3}{l}{ Hồ Yên Sở } \\
\cline { 3 - 6 } & & Log $\mathrm{K}_{\mathrm{D}}$ & Số mẫu & $\log \mathrm{K}_{\mathrm{D}}$ & Số mẫu \\
\hline 1 & PFBA & $1,22 \pm 0,26$ & 4 & $1,30 \pm 0,21$ & 4 \\
2 & PFPeA & $1,42 \pm 0,21$ & 5 & $1,19 \pm 0,46$ & 8 \\
3 & PFHxA & - & & $1,56 \pm 0,50$ & 3 \\
4 & PFOA & $1,05 \pm 0,44$ & 15 & $1,47 \pm 0,41$ & 14 \\
5 & PFNA & $2,10 \pm 0,34$ & 6 & $1,95 \pm 0,48$ & 10 \\
6 & PFDA & 2,01 & 1 & $2,91 \pm 0,83$ & 14 \\
7 & L-PFBS & - & & $1,08 \pm 0,25$ & 2 \\
8 & L-PFOS & $1,99 \pm 0,24$ & 8 & $2,32 \pm 0,34$ & 9 \\
\hline
\end{tabular}

\section{Kết luận}

Nghiên cứu được thực hiện lần đầu tiên về đánh giá sự phân bố và tích lũy của các hợp chất PFCs trong nước và trầm tích hồ Tây và hồ Yên Sở. Nồng độ PFCs trong nước hồ Yên Sở cao hơn hồ Tây gấp 1, 5 lần, còn trong trầm tích cao gấp 7-8 lần. So sánh với tiêu chuẩn của EPA về nước đối với $P F O S$ và $P F O A$ và số liệu đo đạc của một số hồ trên thế giới thì PFCs tại hồ Tây và hồ Yên Sở nằm trong khoảng hàm lượng thấp. Hệ số phân bố PFCs giữa trầm tích và nước có giá trị $\log \mathrm{K}_{\mathrm{D}}$ từ 1,05 tới 2,91 . Sự phát hiện thấy nhóm chất này trong nước và trầm tích tại hai hồ tại Hà Nội hiện đang nuôi cá để phục vụ nhu cầu dân sinh cho thấy cần thực hiện việc kiểm soát môi trường cũng như xác định sự có mặt của nhóm chất này trong cá và các loài thủy sinh khác nhằm đánh giá sự tích luỹ và rủi ro tới sức khỏe con người cũng như môi trường.

\section{Lời cảm ơn}

Nghiên cứu thực hiện trong khuôn khổ dự án "Quan trắc và quản lý các hợp chất POPs ở Châu Á" được điều phối bởi trường Đại học Liên hiệp Quốc UNU và được tài trợ một phần kinh phí từ tập đoàn Shimadzu, Nhật Bản,

\section{Tài liệu tham khảo}

[1] Báo cáo Hiện trạng các chất POP mới ở Việt Nam -Dự án cập nhập kế hoạch quốc gia thực hiện Công ước Stockholm về các chất ô nhiễm hữu cơ khó phân hủy (POPs), Tổng Cục Môi trường, (2015).

[2] Kurunthachalam Kannan, Perfluoroalkyl and polyfluoroalkyl substances: current and future perspectives, Environ. Chem. 8 (2011) 333-338.

[3] lberto Pistocchi and Robert Loos, A map of European emissions and concentrations of PFOS and PFOA. Environ. Sci. Technol. 43 (2009), 9237-9244.

[4] Hongwen Sun, Fasong Li, Tao Zhang, Xianzhong Zhang, Na He, Qi Song, Lijie Zhao, Lina Sun and Tieheng Sun, Perfluorinated compounds in surface waters and WWTPs in Shenyang, China: Mass flows and source analysis, Water Research 45 (2011) 4483-4490.

[5] Water quality - Determination of perfluorooctanesulfonate (PFOS) and perfluorooctanoate (PFOA) - method for unfiltered sample using solid phase extraction and liquid chromatography/mass spectrometry, International standard - ISO-25101, (2009).

[6] UNU Training workshop: Analysis of PFCs in water, sediment and fish by LC/MS/MS method, in the frame of project "Monitoring and Management of POPs in Asia", (2013) and (2016).

[7] Nguyễn Thúy Ngọc, Phan Đình Quang, Lê Hữu Tuyến, Trương Thị Kim, Phùng Thị Vĩ, Phạm Hùng Việt và Dương Hồng Anh, Phân tích nhóm hợp chất peflo hóa trong các loại mẫu môi trường: nước, trầm tích, cá bằng phương pháp sắc ký lỏng khối phổ hai lần, Tạp chí Khoa học ĐHQGHN: Khoa học Tự nhiên và Công nghệ 33(3), (2017) 87-93.

[8] Yali Shi, Yuanyuan Pan, Jieming Wang and Yaqi Cai, Distribution of perfluorinated compounds in water, sediment, biota and floating 
14 (2012) 636-642.

n Lake, China, J. Environ. Monit.

[9] Yuan Zhang, Wei Meng, Changsheng Guo, Jian $\mathrm{Xu}$, Tao Yu, Wenhong Fan, Lei Li, Determination and partitioning behavior of perfluoroalkyl carboxylic acids and perfluorooctanesulfonate in water and sediment from Dianchi Lake, China, Chemosphere 88 (2012) 1292-1299.

[10] Gang Pan, Qin Zhou, Xuan Luan, Q. Shiang Fu, Distribution of perfl uorinated compounds in Lake Taihu (China):Impact to human health and water standards, Science of the Total Environment 487 (2014) 778-784.
[11] Yolanda Pico Ema, Cristina Blasco, Marinella Farré, Damia Barceló, Occurrence of perfluorinated compounds in water and sediment of L'Albufera Natural Park (València, Spain), Environmental Science and Pollution Research 19 (2012) 946-957.

[12] Garry Codling, Anja Vogt, Paul D. Jones , Tieyu Wang, Pei Wang, Y.-L. Lu, Margaret Corcoran, Solidea Bonina, An Li, Neil C. Sturchio, Karl J. Rockne, Kyunghee Jij, Jong-Seong Khim, Jonathan E. Naile, John P. Giesy, Historical trends of inorganic and organic fluorine in sediments of Lake Michigan, Chemosphere 114 (2014) 203209.

\title{
Distribution and Accumulation of Perfluororinated Chemicals (PFCs) in Water and Sediment in Two Urban Large Lakes, Hanoi
}

\author{
Nguyen Thuy Ngoc, Phan Dinh Quang, Truong Thi Kim, \\ Phung Thi Vi, Pham Hung Viet, Duong Hong Anh \\ VNU Key Laboratory of Analytical Technology for Environmental Quality and Food Safety Control \\ (KLATEFOS), VNU University of Science, Vietnam National University, Hanoi
}

\begin{abstract}
The distribution of perfluorinated chemicals (PFCs) in surface water samples $(n=40)$ and sediment samples $(\mathrm{n}=36)$ from West lake and Yen So lake in rainy and dry season were determined. Average concentrations of total PFCs detected in water samples were $10.78 \mathrm{ng} / 1$ (8.13 $13.25 \mathrm{ng} / \mathrm{l})$ in West lake and $14.55 \mathrm{ng} / \mathrm{l}(12.42-17.64 \mathrm{ng} / \mathrm{l})$ in Yen So lake. The total PFCs in sediment samples from West lake and Yen So lake ranged from 0.03 to $0.26 \mathrm{ng} / \mathrm{g}$ dry weight (mean, $0.11 \mathrm{ng} / \mathrm{g}$ ) and from 0.08 to $2.01 \mathrm{ng} / \mathrm{g}$ dry weight (mean, $0.79 \mathrm{ng} / \mathrm{g}$ ), respectively. The results of this study indicated that short-chain PFCs (C4-C10) were the dominant PFCs in water, while long-chain PFCs dominated sediment in both two lakes. PFCs accumulation was found in sediment and water of both Yen So lake and West lake with distribution factor $\left(\log \mathrm{K}_{\mathrm{D}}\right)$ in a range of 1.05 and 2.91.
\end{abstract}

Keywords: PFCs, water, sediment, West lake, Yen So lake. 